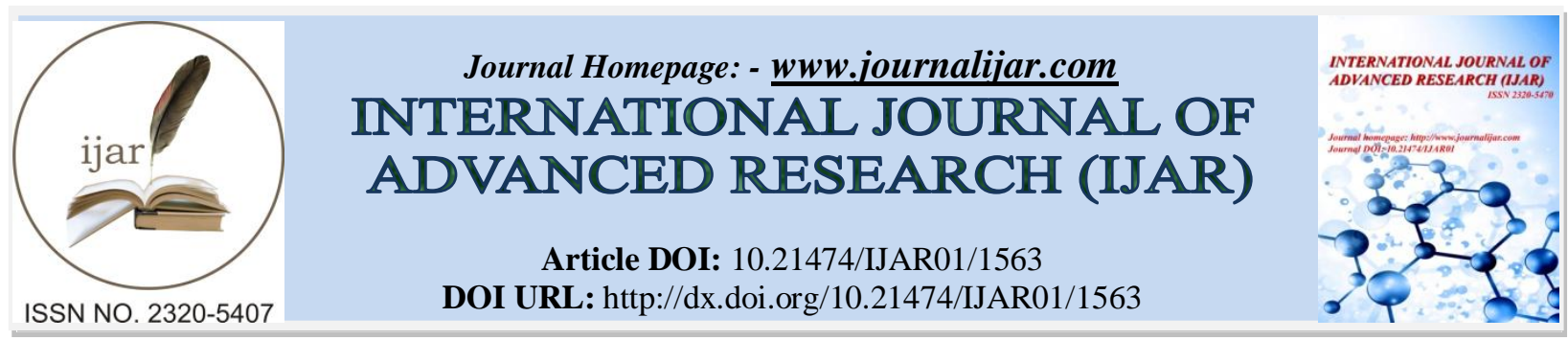

RESEARCH ARTICLE

\title{
EFFECT OF TEMPERATURE ON THERMO PHYSICAL PROPERTIES OF BINARY LIQUID MIXTURE AND ITS EFFECT ON ENVIRONMENT.
}

\author{
*K.Sathya ${ }^{1}$, R. Baskaran ${ }^{2}$ and T. R. Kubendran ${ }^{3}$. \\ 1. Department of Biotechnology, Rajalakshmi Engineering College, Chennai-602105. \\ 2. Department of Chemical Engineering, St.Joseph's College of Engineering, Chennai-600119. \\ 3. Department of Chemical Engineering, A.C. Tech., Anna University, Chennai-600025.
}

\section{Manuscript Info \\ Manuscript History \\ Received: 15 July 2016 \\ Final Accepted: 26 August 2016 \\ Published: September 2016}

Key words:-

Density; Environment; Excess Gibbs free energy; Viscosity

\section{Abstract}

Liquid mixtures have attracted considerable attention due to their unusual behaviour. In pharmaceutical, chemical and biochemical industries, organic compounds are used as an intermediate and are normally handled in fluid form and as a consequence, the transport properties of fluids assume importance due to their environmental impact. The emission of volatile or partially volatile compounds must be reduced to appropriate levels before exposing industrial streams to atmosphere. One of the most widespread technologies used to achieve that reduction is adsorption using suitable adsorbent like activated carbon in a fixed bed. These processes are operated at different temperatures. Design of such operations requires quantitative estimates of transport properties of liquid mixtures. In the present study, densities and viscosities of paraanisaldehyde - propylacetate organic mixture was measured over the entire mole fractions at $308.15,318.15$ and $328.15 \mathrm{~K}$. Studies on determination of different thermo physical properties of liquid mixtures within wide range of composition and temperature are valuable sources of information that might be used to examine relation between the internal structure of the system and its physical properties. Excess Gibbs free energy was obtained at different temperature from the measured properties and the spontaneity of the process was discussed. The impacts of organic compound, based on Gibbs free energy values were also discussed. The positive Gibbs free energy revealed that the adsorption is nonspontaneous and hence the impact on the environment of the binary liquid mixtures paraanisaldehyde - propylacetate is high at 308.15 , 318.15 and $328.15 \mathrm{~K}$.

Copy Right, IJAR, 2016,. All rights reserved.

\section{Introduction:-}

The organic compounds like paraanisaldehyde - propyacetate mixtures are widely used an intermediate in pharmaceuticals and agrochemicals industries. Paraanisaldehyde along with acid and ethanol is frequently used to stain thin layer chromatography plates (Saravanakumar et al., 2012a). The unused organic compounds are discharged as waste in effluent water. The removal of these organic compounds from waste water is essential before the stream are let out or recycled back. Adsorption process is recognized as one of the effective and low cost 
technique for removal of organic pollutants from waste water, and produces high quality treated effluent (Rasheed 2013a). The present work discusses about the feasibility of the treatment of the above waste water at various temperatures based on excess Gibbs free energy of compounds. For the successful design and operation of adsorption process, the data on the thermo physical properties like density and viscosity of the organic liquid mixtures are important to establish. The feasibility studies of the adsorption process for organic liquid mixtures are essential before the adsorption process which involves the excess Gibbs energy calculation. Since no data is reported in the literature, the objective of the present study is to find out the feasibility of the process by estimating excess Gibbs free energy in terms of thermo physical properties like density and viscosity at various temperatures to conclude the impact on environment.

\section{Properties of Organic Compound:- \\ Paraanisaldehyde:-}<smiles>COc1ccc(C=O)cc1</smiles>

Fig .1:- Molecular structure of Paraanisaldehyde.

Paraanisaldehyde is an organic compound that is a clear to slightly yellow oily liquid with strong aroma. Its molecular formula is $\mathrm{C}_{8} \mathrm{H}_{8} \mathrm{O}_{2}$. It occurs naturally in the fennel and anise plants. It is a high volume chemical with production over 1 million pounds annually. The compound consists of a benzene ring with an aldehyde and a methoxy group. It is a clear liquid with a strong aroma (Fahlbush 2003).

Formula: $\mathrm{C}_{8} \mathrm{H}_{8} \mathrm{O}_{2}$

Density: $1.12 \mathrm{~g} / \mathrm{cm}^{3}$

Molar mass: $136.15 \mathrm{~g} / \mathrm{mol}$

Melting point: $0{ }^{\circ} \mathrm{C}$

Boiling point: $248^{\circ} \mathrm{C}$

\section{Propyl acetate:-}

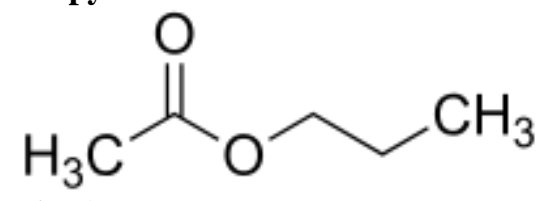

Fig .2:- Molecular structure of Propyl acetate

Propyl acetate is a organic compound used as a solvent. Propyl acetate is clear and colourless liquid is known by its odour of pears. Due to this fact, it is commonly used in fragrances and as a flavour additive.

Formula: $\mathrm{C}_{5} \mathrm{H}_{10} \mathrm{O}_{2}$

Density: $0.89 \mathrm{~g} / \mathrm{cm}^{3}$

Molar mass: $102.13 \mathrm{~g} / \mathrm{mol}$

Melting point: $-95^{\circ} \mathrm{C}$

Boiling point: $102^{\circ} \mathrm{C}$

\section{Impact on Environment:-}

* Volatile organic compounds (VOCs) are gases or vapours emitted by various solids and liquids, many of which have short- and long-term adverse effects on human health and the environment. VOCs from petroleum are toxic and foul the air, extremely toxic, carcinogenic and cause DNA damage (Rasheed 2013b).

- Major sources of man-made VOCs are coatings, especially paints and protective coatings. Solvents are required to spread a protective or decorative film. Approximately 12 billion litres of paints are produced annually. Typical solvents are aliphatic hydrocarbons, propyl acetate, glycol ethers, and acetone (Luo et al., 2013). 
* Respiratory, allergic, or immune effects in infants are associated with man-made VOCs and other indoor or outdoor air pollutants. Health effects include eye, nose, and throat irritation; headaches, loss of coordination, nausea; and damage to the liver, kidney, and central nervous system. Some organics can cause cancer in animals; some are suspected or known to cause cancer in humans. Key signs or symptoms associated with exposure to VOCs include conjunctival irritation, nose and throat discomfort, headache, allergic skin reaction, dyspnea, declines in serum cholinesterase levels, nausea, vomiting, nose bleeding, fatigue, dizziness.

- Many organic compounds are known to cause cancer in animals; some are suspected of causing, or are known to cause, cancer in humans (Huiping et al., 2014).

- Short-term exposure to high levels of alkyl acetate results first in irritation of the eyes, nose and throat, followed by headache, nausea, vomiting, sleepiness, and unconsciousness. Very high concentrations may cause a stupor. Prolonged exposures may cause clouding of the eye, damage to the lung, heart, kidney and liver problems. (Wolkoff et al. 2007).

* Paraanisaldehyde is a suspected neurotoxicant according to the Registry of Toxic Effects of Chemical Substances. (Wolkoff et al. 2006)

\section{Experimental Methods:-}

All the chemicals (paraanisaldehyde- propyl acetate ) used in this study were of analytical grade and obtained from Lobo Chemicals, India. The claimed mass fraction purity of the chemicals was $\geq 0.998$. These chemicals were dried over molecular sieves and partially degassed prior to use (Perrin et al,1998; Saravanakumar et al., 2012b). The purity of these experimental chemicals was checked by comparing the observed densities, viscosities with those reported in the literature.

Binary mixtures were prepared by mixing appropriate volumes of the liquid components in the specially designed glass bottles with air tight Teflon coated caps and mass measurements performed on a Shimadzu Corporation Japan type BL 2205 electronic balance, with a precision of $\pm 0.01 \mathrm{mg}$. The required properties were measured on the same day immediately after preparing each composition. The uncertainty of mole fraction were \pm 0.001 . For all the measurements, temperatures were controlled by circulating the water through a thermostat (Technico, Madras. made in India) keeping temperature fluctuations within $\pm 0.03 \mathrm{~K}$. (Bindhani et al., 2014)

\section{Density:-}

Densities were determined by using a $25 \mathrm{~cm}^{3}$ bicapillary pycnometer and calibrated with deionized double distilled water with a density of $996.0 \mathrm{~kg} . \mathrm{m}^{-3}$ at a temperature of $308.15 \mathrm{~K}$. The pycnometer was thermostatted in a transparent walled water bath (maintained constant to $\pm 0.01 \mathrm{~K}$ ) for $15 \mathrm{~min}$ to attain thermal equilibrium, and the level of liquid in the two arms was obtained with a travelling microscope which could read up to $0.01 \mathrm{~mm}$. The precision of the density measurements was estimated to be $\pm 0.003 \mathrm{~g} \cdot \mathrm{cm}^{-3}$ (Saravanakumar et al., 2012c).

\section{Viscosity:-}

Viscosities were measured with Ostwald viscometer previously calibrated using water. The time was measured with a precision of $0.01 \mathrm{~s}$, and the uncertainty in the viscosity was estimated to be less than $0.003 \mathrm{mPa} \cdot \mathrm{s}$. The kinematic viscosity was obtained from the working equation

$\vartheta=a t+b / t$

Where, the two constants a and $\mathrm{b}$ were obtained by measuring the flow time $\mathrm{t}$ of benzene.

( Saravanakumar et al., 2012d).

Excess Gibbs free energy of binary mixture was obtained from the following equation

$\Delta \mathrm{G}^{\mathrm{E}}=\mathrm{RT}\left[\ln (\eta \mathrm{V})-\left(\mathrm{X}_{1} \ln \left(\eta_{1} \mathrm{~V}_{1}\right)+\mathrm{X}_{2} \ln \left(\eta_{2} \mathrm{~V}_{2}\right)\right)\right]$

where, $\mathrm{R}$ is the universal constant of gases; $\mathrm{T}$ is the absolute temperature, $\mathrm{V}_{1}$ and $\mathrm{V}_{2}$ are the molar volumes of component 1 and $2 ; \mathrm{x}_{1}$ and $\mathrm{x}_{2}$ represents the mole fraction of component 1 and $2 . \mathrm{V}_{\mathrm{m}}$ was obtained from equation (3). $\eta_{1}, \eta_{2}$ and $\eta_{m}$ are the viscosity of component 1 and 2 and mixture, respectively.

$\mathrm{V}_{\mathrm{m}}=\mathrm{x}_{1} \mathrm{~m}_{1}+\mathrm{x}_{2} \mathrm{~m}_{2} / \rho_{\mathrm{m}}$

Where, $\rho_{\mathrm{m}}$ is the density of mixture (Mardones et al., 2014). 


\section{Results and Discussion:-}

Measured values of densities and viscosities of paraanisaldehyde- propyl acetate binary liquid mixture at different temperature are shown in Fig. 3, and 4. The result showed that the decrease in density and viscosity with temperature. It was due to more molecular interaction between the binary liquid mixture (Saravanakumar et al., 2012e; Saravanakumar et al., 2011). Effect of temperature on density and viscosity is considered important, because excess Gibbs free energy is mainly depend on these properties and is calculated from the measured experimental data.

Excess Gibbs free energy provides information about the molecular interactions and macroscopic behaviour of fluid mixtures which can be used to test and improve thermodynamic models for calculating and predicting fluid phase equilibrium (Mchaweh et al., 2004). The magnitude of excess Gibbs free energy represents the strength of interaction between unlike molecules (Riddick 1986; Perrin 1988; Gales and Mendes 2000).

The Gibbs free energy change indicates the degree of spontaneity of an adsorption process. The negative and positive value reflects favourable, as well as unfavourable adsorption. The Gibbs free energy has been also used to find equilibrium constant in adsorption studies of organic compound. (Gales and Mendes 2000; Mardones et al., 2014; Setiyanto et al., 2013; Liu 2009).

The effect of temperature on Excess Gibbs free energy for paraanisaldehyde- propyl acetate binary system is shown in Fig. 5, 6 and 7. Excess Gibbs free energy was found to be positive for all temperatures. The positive values of excess Gibbs free energy of binary mixture indicate the presence of specific and strong interactions in the systems (Ezekiel et al., 2012; Kondaiah and Krishna Rao 2013). Positive Gibbs free energy indicates the non-spontaneous nature of the process. A positive value of Gibbs free energy revealed that there was an energy barrier. When the ions enter from the solution into the particle surface, some of the water molecules forming hydration shell of ions were stripped off and simultaneously the degree of freedom of ions decreased. So feasibility of the process was reduced. Hence, the adsorption did not occur or adsorption will be endothermic in nature (Ayar et al., 2008). So treatment of these types of organic mixtures is not feasible at 308.15, 318.15 and $328.15 \mathrm{~K}$. The impact of these compounds on environment could not be reduced easily due to non spontaneity nature or less feasibility.

\section{Summaries:-}

Hence, densities and viscosities for organic binary mixtures were measured experimentally at different temperature over wide concentration range. The effects of temperature on densities, viscosities and excess Gibbs free energies on mixture were reported in Fig.3, 4, 5, 6,7, 8 and 9. Positive Gibbs free energy indicates the non-spontaneous nature of the adsorption process involves in the treatment of effluent waste water. It revealed that the impact of paraanisaldehyde- propyl acetate binary system on environment would be high at 308.15, 318.15 and $328.15 \mathrm{~K}$.

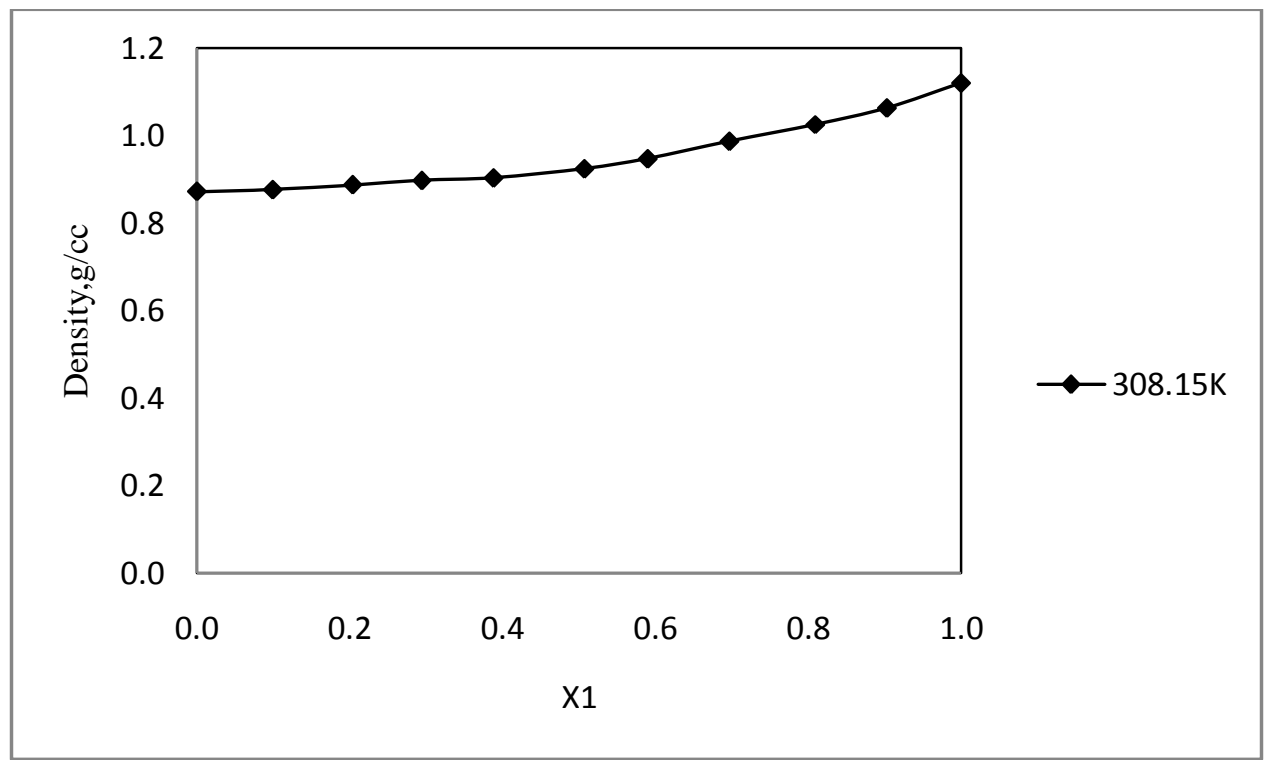

Fig .3:- Effect of temperature on density for $\quad[p$-anisaldehyde (1) + propyl acetate (2)] 


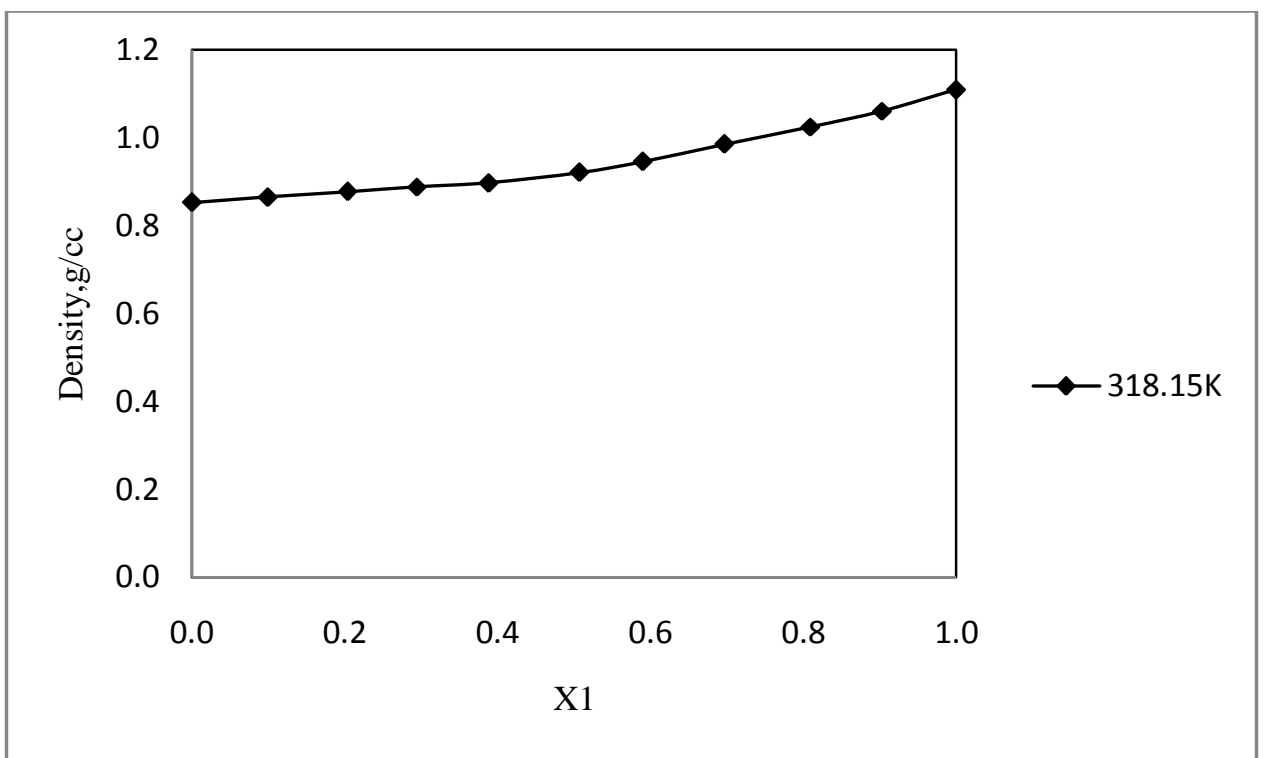

Fig .4:- Effect of temperature on density for [p-anisaldehyde (1) + propyl acetate (2)]

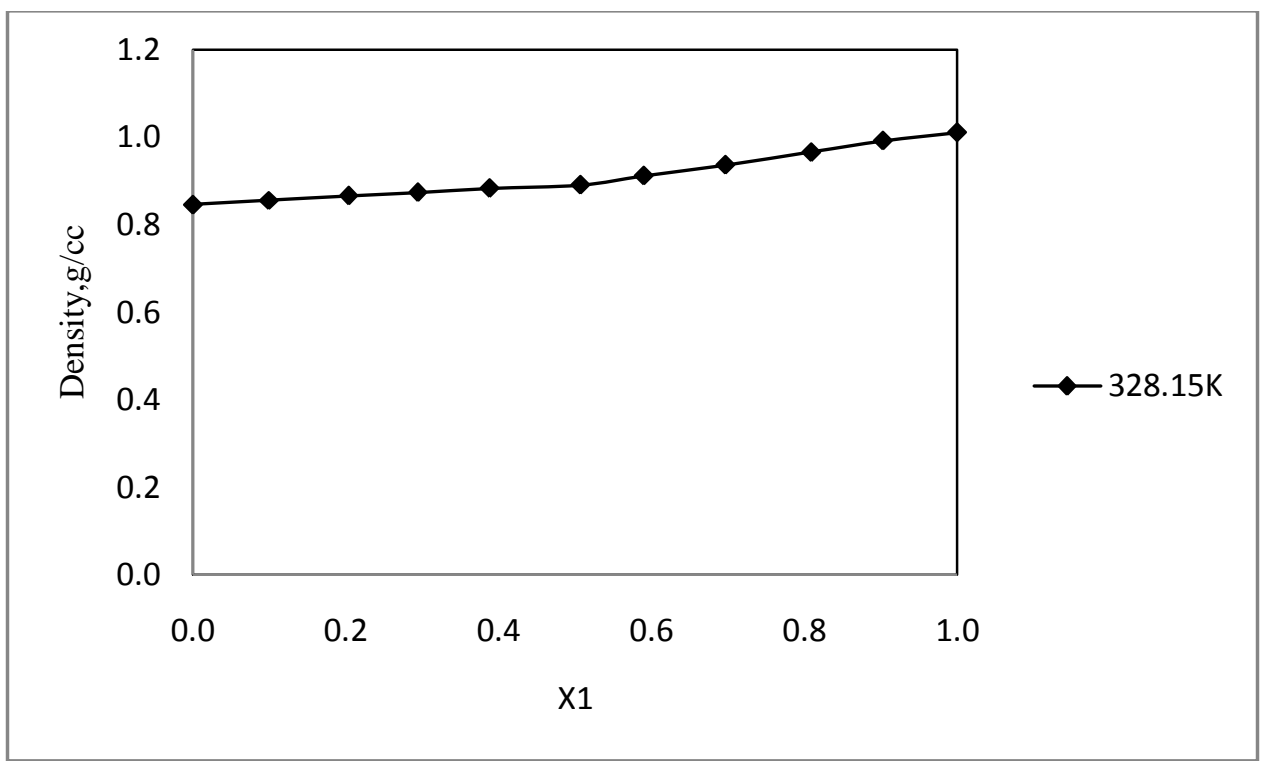

Fig .5:- Effect of temperature on density for [p-anisaldehyde (1) + propyl acetate (2)] 


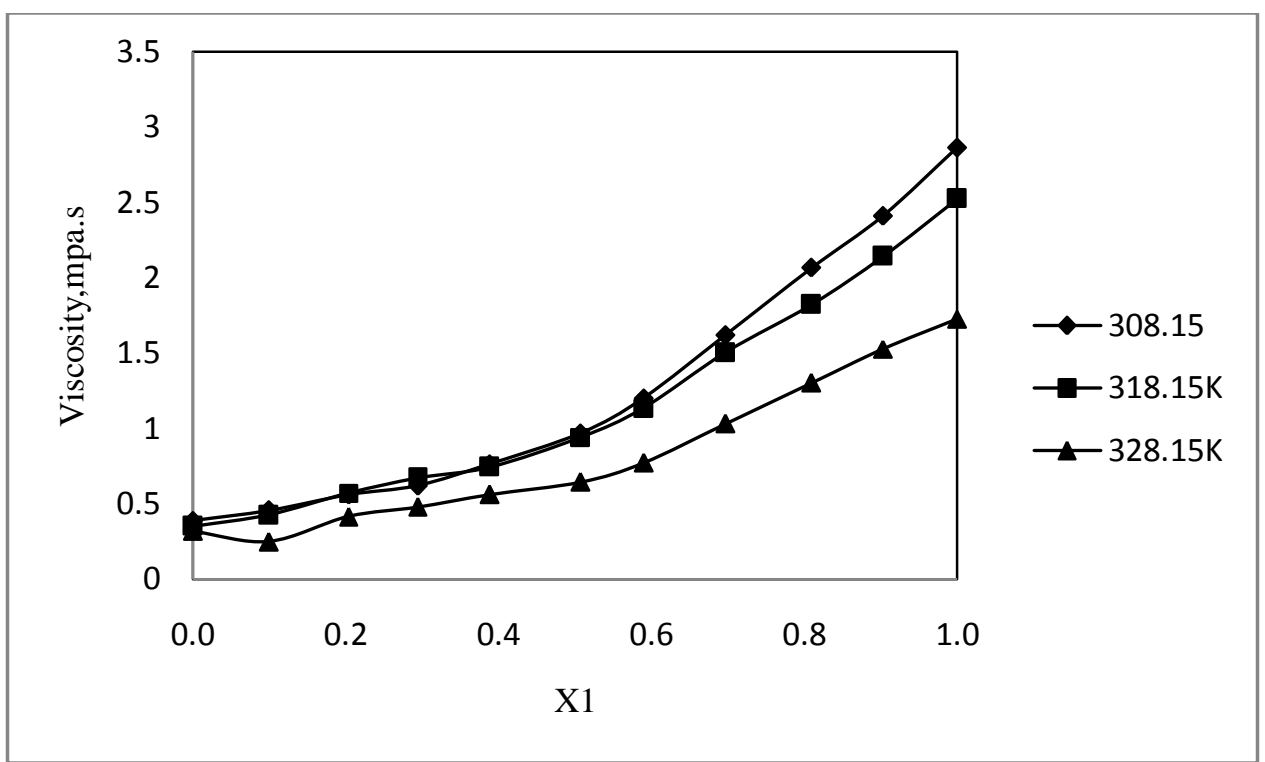

Fig. 6:- Effect of temperature on viscosity for [p-anisaldehyde (1) + propyl acetate (2)]

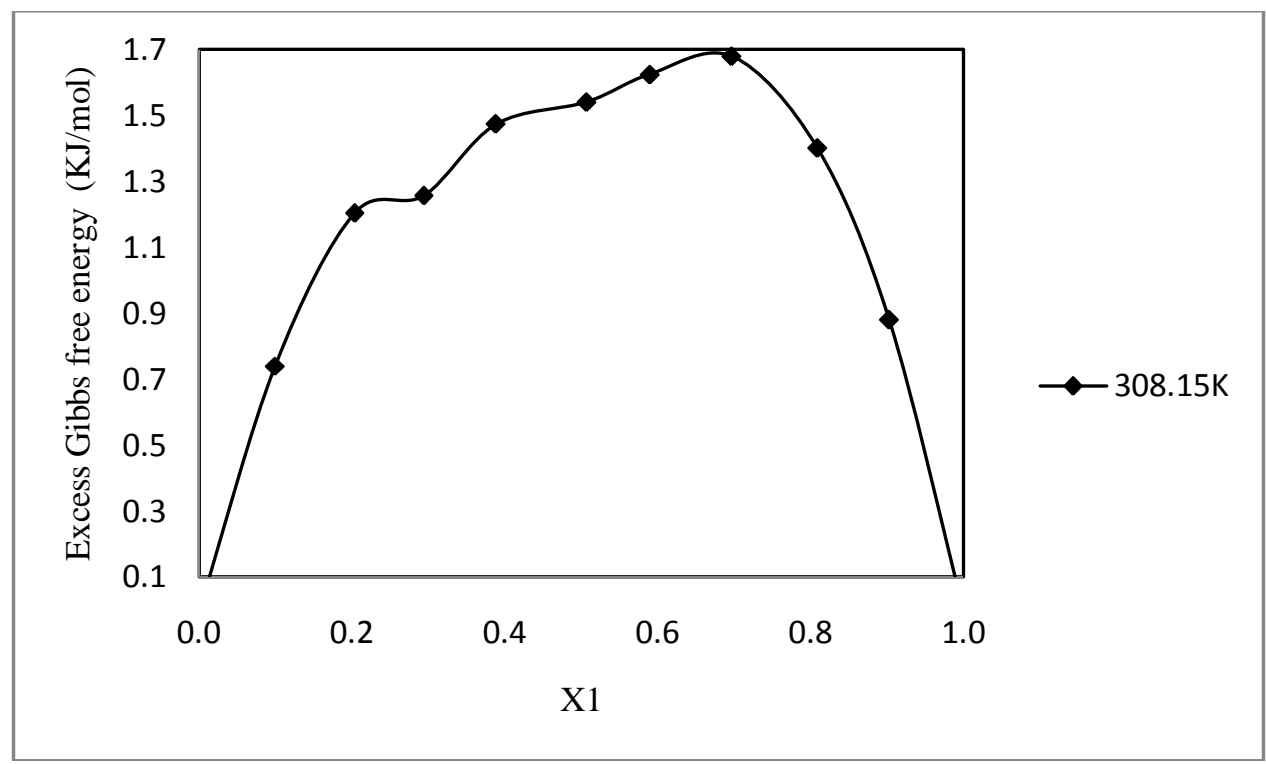

Fig. 7:- Effect of temperature on Excess Gibbs free energy at 308.15K for [p-anisaldehyde (1) + propyl acetate (2)] 


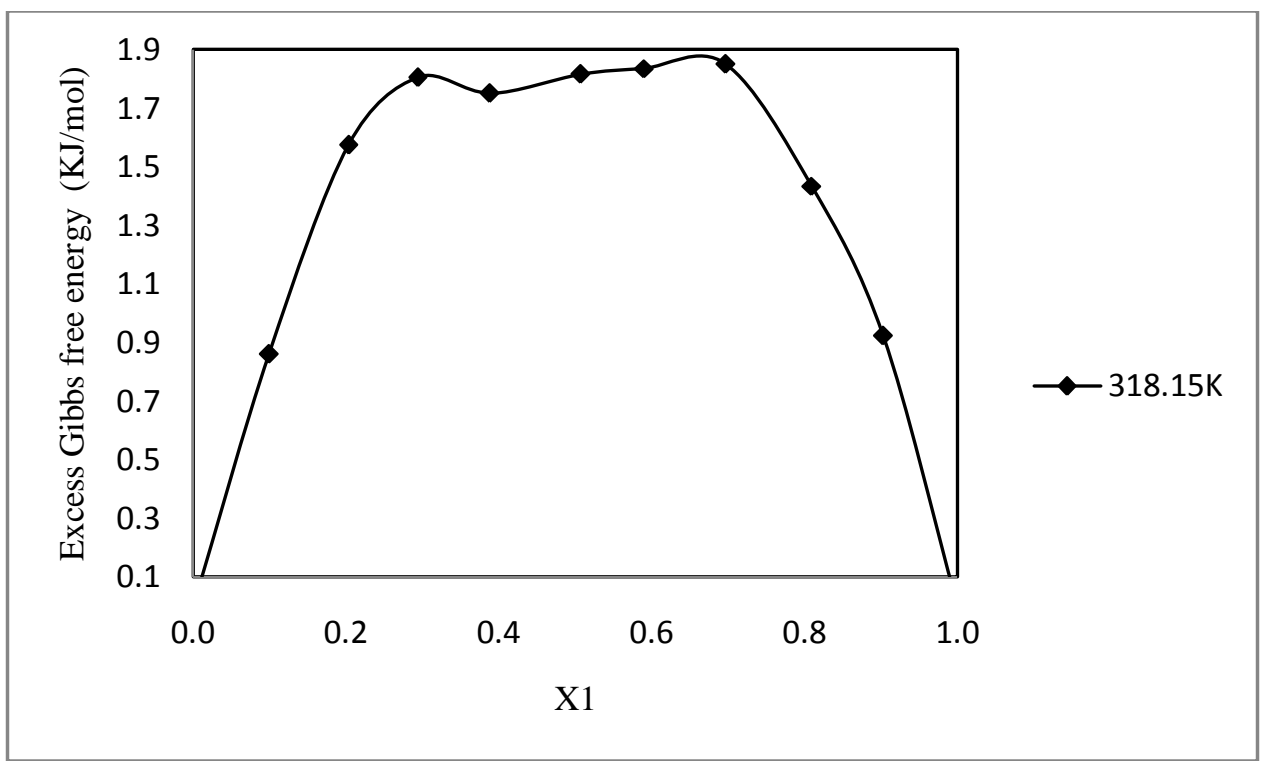

Fig.8:- Effect of temperature on Excess Gibbs free energy at 318.15K for [p-anisaldehyde (1) + propyl acetate (2)]

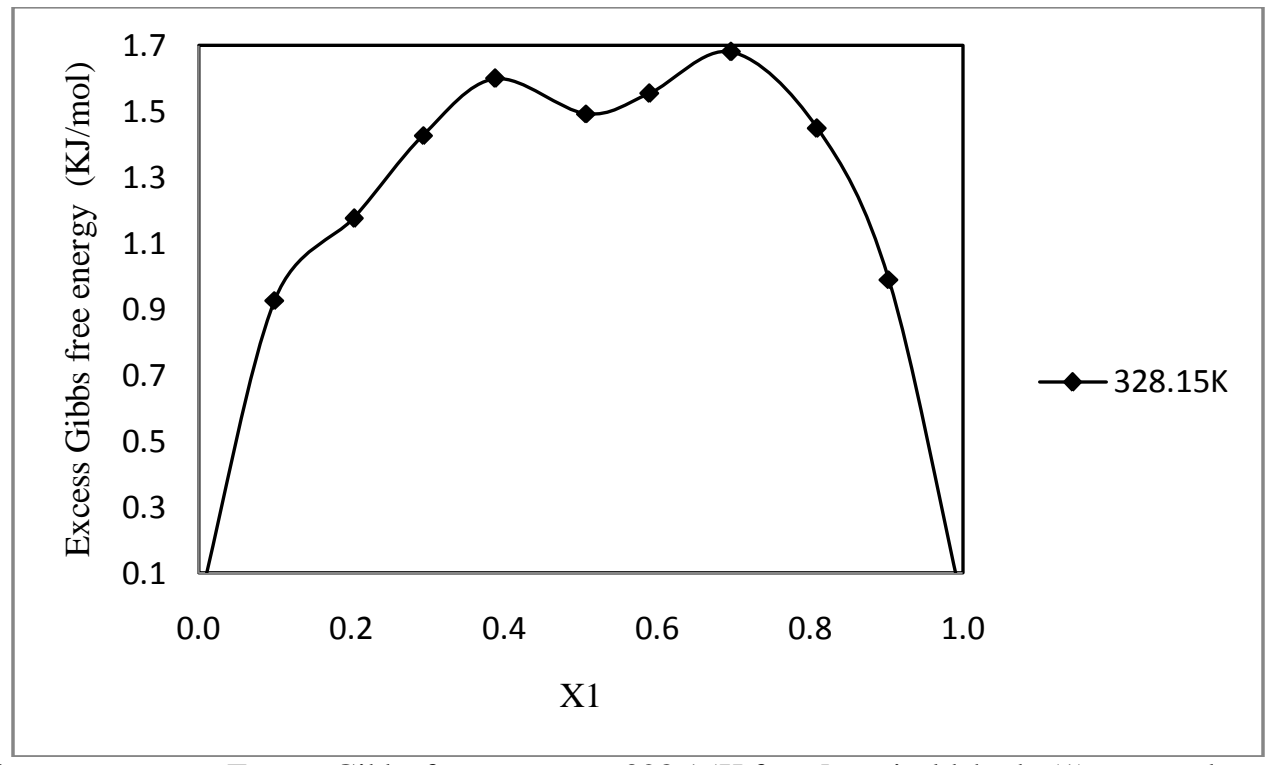

Fig. 9:- Effect of temperature on Excess Gibbs free energy at 328.15K for [p-anisaldehyde (1) + propyl acetate (2)]

\section{Acknowledgment:-}

The authors thank the Institute authorities for providing the necessary facilities to carry out the work.

\section{References:-}

1. Ayar, N., B.Bilgin and G. Atun. (2008). Kinetics and equilibrium studies of the herbicide 2,4dichlorophenoxyacetic acid adsorption on bituminous shale. Chem. Engg. J. 138, 239-248.

2. Baskaran,R., and T. R.Kubendran.(2008).Thermo Physical Properties of 4-Hydroxy 4-Methyl

3. Pentanone with Nitrobenzene or Ethyl Benzene at Temperatures of (303.15, 313.15 and 323.15) K and a Pressure of 0.1 MPa. J. Chem Engg. Data., 53,1956.

4. Bindhani, K., G. K. Roy, Y. K. Mohanty and T. R. Kubendran. (2014). Effect of Temperature and Concentration on Density, Viscosity and Ultrasonic Velocity of the Binary Liquid Mixture. Russian J. Phy. Chem. A. 88, 1255-1264. 
5. Ezekiel, D. D., S. M. Nelana, D. A. Isabirye and E. E. Ebenso. (2012). Density, dynamic viscosity and derived properties of binary mixtures of methanol, ethanol, n-propanol, and n-butanol with pyridine at $\mathrm{T}=(293.15$, 303.15, 313.15 and 323.15) K. Int. J. Electrochem.Sci.7, $11101-11122$.

6. Fahlbusch, K. G., F. J. Hammerschmidt, J. Panten, W. Pickenhagen, D. Schatkowski, K. Bauer, D. Garbe and H. Surburg.(2003). Flavors and Fragrances in Ullmann's Encyclopedia of Industrial Chemistry. Wiley-VCH, Weinheim.1.

7. Gales, L., A. Mendes and C. Costa (2000). Hystersis in the cyclic adsorption of acetone, ethanol and ethyl acetate on activated carbon. Carbon. 38,1083-1088.

8. Muhammad Ali Zulfikar and Henry Setiyanto.(2013). Study of the adsorption kinetics and thermodynamic for the removal of congo red from aqueous solution using powdered eggshell. Int. J.Chem. Tech. Res. 5,1671-1678.

9. Huiping, S., C. Huaigang, Z. Zepeng and C. Fangqin.(2014).Adsorption properties of zeolites synthesized from coal fly ash for $\mathrm{Cu}$ (II). J. Environ. Biol. 35, 983-988.

10. Kondaiah, M., and Krishna Rao, D. (2013). Correlation of excess molar volumes with Redlich - Kister polynomial and evaluation of partial molar volumes, excess partial molar volumes in some binary mixtures at 308.15 K. Int. J. Res. Pure Appl. Phy. 3.

11. Luo, D., Y. Xie, Z. L. Tan and X. D. Li .(2013). Removal of $\mathrm{Cu}^{2+}$ ions from aqueous solution by the abandoned mushroom compost of Flammulina velutipes. J. Environ. Biol. 34, 359-365.

12. Mchaweh, A., A. Alsay and M.A. Moshfeghian. (2004).Simplified method for calculating saturated liquid densities. Fluid Phase Equilib. 224, 157-167.

13. Mónica García-Mardones, Santiago Martín, Ignacio Gascón, and Carlos Lafuente. (2014). Thermophysical properties of the binary mixture 1-propylpyridinium tetrafluoroborate with methanol. J. Chem. Engg. Data. 59, 1564-1573.

14. Perrin, D. D., and W. L. F. Armerego.(1988). Purification of Laboratory chemistry. $3^{\text {rd }}$ Edition Pergamon press: Oxford.

15. Rasheed, M. N. (2013). Organic Pollutants- Monitoring, Risk and Treatment. InTech.

16. Riddick J A., W. B. Bunger, T. K. Sakano. (1986). Organic solvents- physical properties and methods of purification. $4^{\text {th }}$ Edition Wiley- Interscience: New York .

17. Saravanakumar, K., R. Baskaran and T. R. Kubendran. (2011). Thermo physical properties of acetophenone with $\mathrm{N}, \mathrm{N}$-dimethylethanolamine or with $\mathrm{N}, \mathrm{N}$-diethylethanolamine at temperatures of $(303.15,313.15$ and 323.15) K and Pressure of 0.1 MPa. J. Soln.Chem. 40, 955-967 .

18. Saravanakumar, K., T. G. Lavanya, R. Baskaran and T. R. Kubendran. (2012). Thermophysical and thermoacoustical properties of benzaldehyde with ethyl benzene at 303.15, 308.15and $313.15 \mathrm{~K}$ and a pressure of 0.1 MPa. Russian J. Phy. Chem . 86, 647-655.

19. Saravanakumar, K., T. G. Lavanya, R. Baskaran and T. R. Kubendran. (2012).Thermo-physical properties of the binary mixture of benzaldehyde with bromobenzene at 303.15, 308.15 and 313.15 K. J. Iran. Chem. Soc., 9 , 277-283.

20. Wolkoff, P., Wilkins, C. K. Clausen, P. A. Nielsen, G. D. (2006).Organic compounds in office environments sensory irritation, odour, measurements and the role of reactive chemistry. Indoor Air. 16, 7-19.

21. Wolkoff, P., Kjaergaard, Soren K. (2007). The dichotomy of relative humidity on indoor air quality. Environ. Int. 33, 850-857.

22. Y. Liu. (2009).Is the free energy change of adsorption correctly calculated?. J. Chem. Engg. Data. 54, 1981-1985. 